\title{
Éducation à l'environnement : nouveaux
} publics, nouveaux partenaires

3 et 4 mai 2000 - Ifrée, Colloque de Poitiers (France)

Jean Burger

\section{OpenEdition}

\section{Journals}

Édition électronique

URL : http://journals.openedition.org/ere/7012

DOI : $10.4000 /$ ere.7012

ISSN : 2561-2271

Éditeur

Centr'ERE

Référence électronique

Jean Burger, «Éducation à l'environnement : nouveaux publics, nouveaux partenaires », Éducation relative à l'environnement [En ligne], Volume 2| 2000, mis en ligne le 15 septembre 2000, consulté le 17 avril 2021. URL : http://journals.openedition.org/ere/7012 ; DOI : https://doi.org/10.4000/ere.7012 


\section{Éducation à l'environnement : nouveaux publics, nouveaux partenaires}

3 et 4 mai 2000 - Ifrée, Colloque de Poitiers (France)

\section{Jean Burger}

1 Près de 80 personnes étaient réunies au Futuroscope de Poitiers: chercheurs et praticiens de l'éducation à l'environnement venus de tous les horizons (10 pays présents), travaillant dans des Universités, des IUFM, des établissements d'enseignement, des ONG internationales, des associations d'éducation à l'environnement et de protection de la nature et également dans des collectivités territoriales.

2 Les objectifs de ce colloque qui faisait suite aux Assises nationales de l'Éducation à l'Environnement de Lille étaient :

- établir des passerelles entre praticiens et chercheurs ;

- faire le point sur la question du partenariat à travers des exemples dans différents champs de l'éducation et de la formation;

- mieux comprendre comment l'éducation à l'environnement s'élargit actuellement à de nouveaux publics, dans les collectivités territoriales, les entreprises, les écoles d'ingénieurs, etc.;

- alimenter le contenu du volume 3 de la revue «Éducation relative à l'environnement: Regards - Recherches - Réflexions ».

3 Il a permis d'aborder les questions du partenariat et des «nouveaux publics » pour l'ERE sous différents angles :

- Quels partenariats avec l'école?

- Quelle intégration des enjeux culturels?

- ERE et insertion sociale ;

- ERE et formation professionnelle ;

-ERE et collectivités territoriales. 
4 rencontrer les points de vue des praticiens et des chercheurs.

5

Ce colloque était organisé par :

- l'Ifrée ;

- le Rectorat de Poitiers (Mission Academique a I'Action Culturelle (MAAC) et Inspection Pedagogique) ;

- l'IUFM (Institut Universitaire de Formation des Maitres) de Poitou-Charentes ;

- le CEP (Centre d'Experimentation Pedagogique) de Florac pour le réseau d'éducation à l'environnement et au développement durable de l'enseignement agricole.

Sous le patronage scientifique de nos partenaires de la revue «Éducation relative à l'environnement: Regards - Recherches - Reflexions»: Louis Goffin, Fondation Universitaire Luxembourgeoise (Belgique); Lucie Sauvé, Universite du Québec a Montréal (Canada) ; Moussa Batchily Ba, Institut du Sahel a Bamako (Mali) et de Maryse Clary, Maitre de conférence a l'IUFM de 'Academie d'Aix Marseille.

7 II a été soutenu financièrement par :

- le Conseil Regional Poitou-Charentes ;

- le Ministere de l'Amenagement du Territoire et de l'Environnement (DIREN PoitouCharentes) ;

- le Ministere de l'Agriculture et de la Peche (DGER) ;

- l'IUFM Poitou-Charentes.

8 Les actes de ce colloque seront disponibles sur CD-rom.

\section{AUTEUR}

JEAN BURGER

Ifrée, Poitou-Charentes, France 